UDC: 004.45

Original scientific paper

\title{
EVALUATION OF ARIS AND ZACHMAN FRAMEWORKS AS ENTERPRISE ARCHITECTURES
}

\author{
Melita Kozina \\ University of Zagreb,Faculty of Organization and Informatics, Varaždin, Croatia \\ melita.kozina@foi.hr
}

\begin{abstract}
The significance of integral business systems based on closer alignment of information technology to business processes has grown over the last ten years. Comprehensive business frameworks are necessary to capture the entire complexity of such systems. These frameworks called enterprise architectures can provide the conceptual foundation necessary for building and managing the integral business system and all its components. The goal of this paper was to analyze the Architecture of Integrated Information Systems (ARIS) and the Zachman frameworks, to define the criteria for comparison and evaluation of these approaches, and determine their level of complement. Furthermore, the contents of the paper define the generic model of business system management supported by said concepts (frameworks) and analyzes their orientation towards value.
\end{abstract}

Key words: enterprise architectures, ARIS, Zachman's framework, business system management.

\section{INTRODUCTION}

Structured frameworks called enterprise architectures capture and manage the complexity of modern organizations. Today, modern organizations are based on connectivity of the business system model and its relevant information system (IS) model. Such integral business systems are highly complex systems consisting of elements such as objectives, data, people, processes, technology. These systems require coordination and integration in order to manage the existing interdependencies between all these elements.

Enterprise architecture frameworks present a conceptual map necessary for building an integral business model supported by the relevant IS. It requires identification information about the organization from different perspectives (views). The main perspectives are: data, functions, networks, organizational structures, schedules and strategy. Each of there business perspectives gradually get implemented into the components of a future IS. This process is supported by 
the second dimension of the conceptual map containing certain phases (levels). Consistently, frameworks support various management tasks such as business process improvement, workflow management, software engineering and in general, business system management.

Building enterprise architectures involves modelling techniques in order to capture the organization in its entirety, an adequate methodology to establish a basis for business system management, and a lifecycle concept of IS as well as integrated modelling tool in order to build and maintain these architectures.

This paper analyzes two important frameworks for enterprise architecture: the Architecture of Integrated Information Systems (ARIS) and the Zachman framework. The goal of this paper is to compare these approaches according to defined criteria, to determine the points of their complement and to assess how efficient this approach is to business system management. In order to solve this, in the paper we describe the general phases of business system management (Chapter 2), analyze, compare and evaluate ARIS and Zachman frameworks (Chapters 3,4) and define the generic model of business system management supported by said architectures (Chapter 5).

\section{BUSINESS SYSTEM MANAGEMENT}

One of the characteristics of the business system management is continuous optimization of business processes and relevant IS implementation. The following process changes could become necessary for business process optimization (business process improvement): changing the process structure; changing organizational structure and responsibilities; changing the data in use; discussing possible outsourcing measures (shifting from internal to external output creation); implementing new production and IT resources to improve processing functions. Figure 1 shows the procedural model of business system management. Through the entire management, we can recognize two main levels: business level and IS development/implementation level.

The starting point of the entire process is the strategic plan and the goals of the business system, for which an adequate IS is developed. Business applications need to support the realization of business goals, which is why information needs stem from the business technology model.

Business process design (AS-IS model)/ redesign (TO-BE model) aims to achieve the greatest efficiency possible in terms of business-organizational solutions. When engineering optimal business processes, different models (diagram techniques) can be provided using ARIS/Zachman architectures and adequate integrated tools and methods. This is the only way to get a picture of the existing process and all its aspects (AS-IS model). 


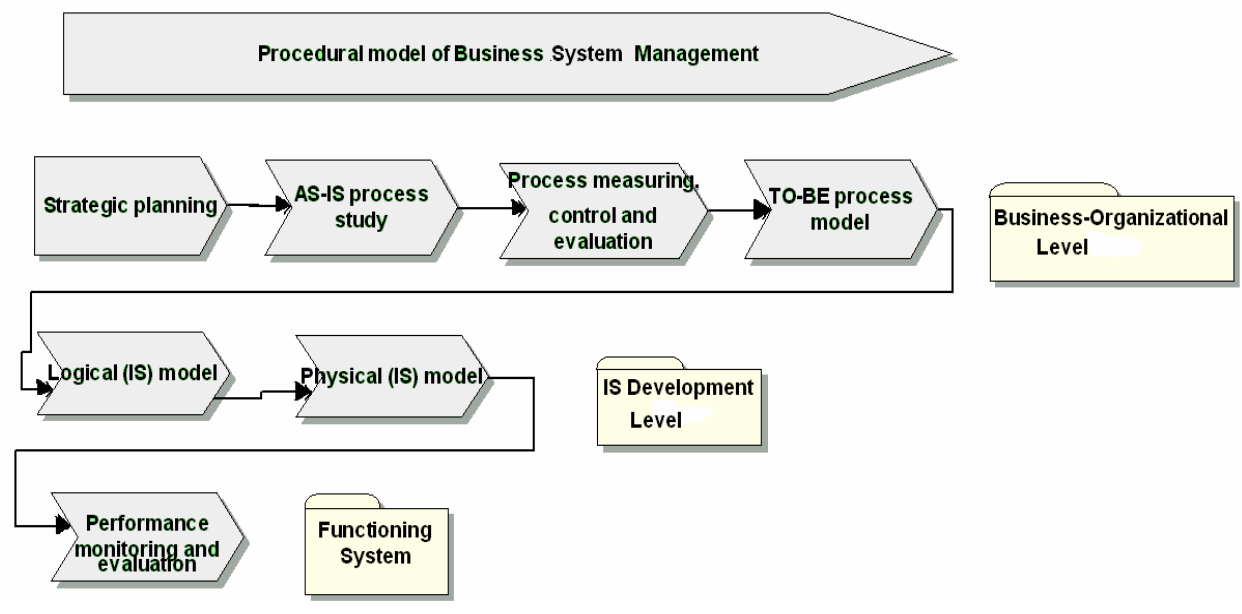

Figure 1. Procedural model of Business System Management

The reference models can be also included, along with available knowledge on best practices. It is also possible to compare alternative procedures (benchmarking) or carry out simulation studies. Multiple alternatives are generated, studied and analyzed in simulation studies in order to engineer the best possible business process. Defining and analyzing the various engineering alternatives in "what-if" situations are also necessary. In dynamic simulations the dynamic behaviour of process alternatives is studied. Furthermore, ICT innovations can also have an effect on the new design of business processes. For example, if the firm in question should implement standard integrated software, the business model would be customized using standard reference models. Also available are various methods for ensuring the quality of the processes (like ISO9000).

In order to design business processes in accordance with specific goals, they must be evaluated in accordance with process goals. Data obtained from lower management levels ensure the basis for process evaluation. Measuring, controlling and evaluating business processes ensure data on efficiency of business processes, resource utilization, process throughput times, process qualities and process costs. By changing process priorities, resource allocations and processing sequences in order to achieve the process goals, process owners can manipulate the process itself. In order to be able to plan and control current business processes, the appropriate information must be made available to the persons responsible for the process. This is why ARIS/Zachman concepts and compatible integrated tools and methods are being used. For example, an efficient method for cost structure analysis is the ABC method (Activity Based Costing). Measuring and evaluating business processes visualize various reasons for redesign (TO BE model) and for linking design and controlling/evaluating phases with one another.

The next important phase in further development of the integrated business system is the development of logical and physical models of the future IS, i.e. gradual transformation of business aspects into IS components. So constructed 
integrated business system demands continuous performance measuring and evaluation aimed at checking the efficacy of business applications in the realization of business goals. Furthermore, it is a good base for further AS-IS studies and new optimization of business processes (TO BE model).

\section{ENTERPRISE ARCHITECTURE FRAMEWORKS}

\subsection{EVOLUTION OF ENTERPRISE ARCHITECTURE}

The concept of enterprise-wide information technology architecture was developed very quickly. The concept included Application, Data and Technology Architectures. As a result, the enterprise architecture became software oriented and application development oriented. However, it was still not enough, since a good alignment between business processes and requests, i.e. needs, as the starting point in the design of IT solutions, could not be established. Therefore, to ensure effective mappings and requirements tracing, business architecture was incorporated into the concept.

The merging of business and IT concepts was a big step forward in the evolution of the enterprise architecture. Although the developed architectures were still too technically-oriented, the alignment between the business needs and IT solutions grew none the less. Business elements such as functions, processes, organizational units and users were introduced to ease the task of software requirements analysis and to increase the quality of application development results. Fig. 2 shows a classic case of enterprise architecture.

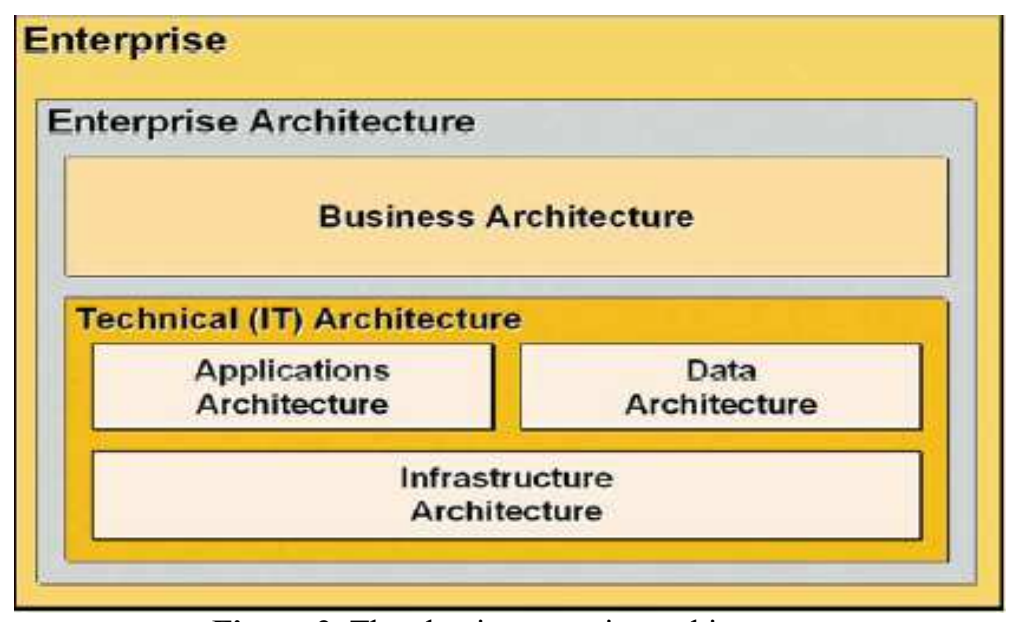

Figure 2. The classic enterprise architecture

Further development found the emergence of comprehensive IT oriented enterprise architecture comprised of Business Process, Organizational and Business Performance Architectures (performance metrics on strategic, operational and human levels). There are many benefits of such architectures such as [3]: 
- Faster response to environmental threat or opportunity;

- Better alignment of change initiatives with enterprise strategy;

- Better alignment of application systems with business objectives and needs;

- Reduced application development lifecycles;

- Reduced application maintenance costs;

- Improved operating procedures.

Fig. 3 shows the balanced enterprise architecture concept.

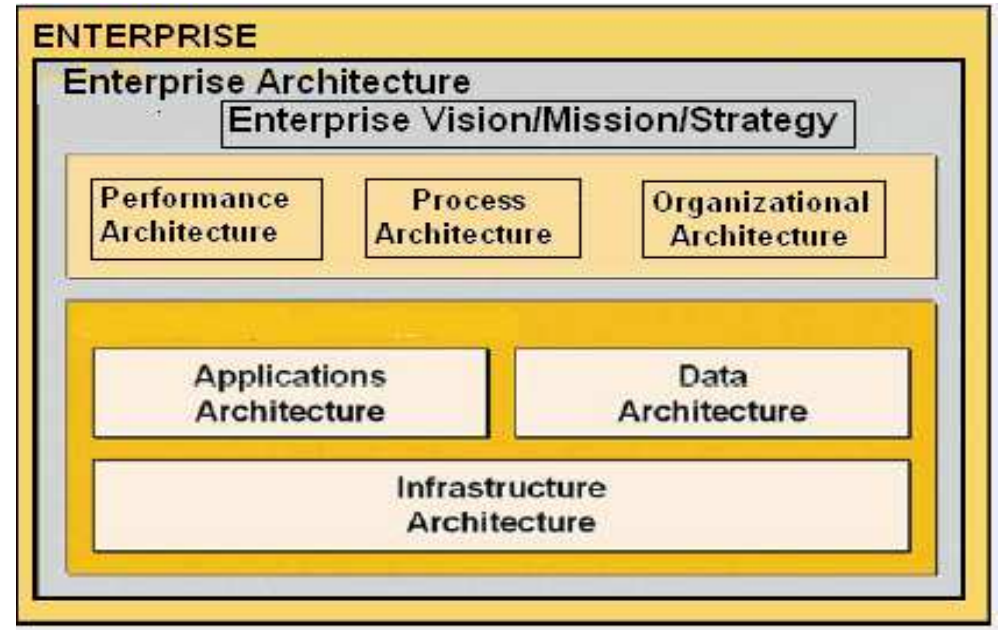

Figure 3. The balanced enterprise architecture

\subsection{THE ARIS FRAMEWORK}

Business process model aimed at modelling and optimization is very complex. With that in mind, the ARIS concept (ARIS: Architecture of Integrated Information Systems) allows us to reference the following important business aspects (meta-classes) [4]:organizational units; corporate goals; initial and result events; messages; functions; material output, service output and information services; financial resources; machine resources and computer hardware; application software; human output; process environmental data. In order to reduce complexity, meta-classes with similar semantic interrelationships are grouped into ARIS views $[4,7,9]$. The grouping of classes and their relationships into views serves the purpose of structuring business process models. Figure 4 shows five different views.

FUNCTION VIEW -HOW, WHY: the processes transforming input into output are grouped in a function view. Due to the fact that functions support goals, goals are also allocated to function view. In application software, computer-aided processing rules of a function are defined. Thus, application software is closely aligned with functions, and is also allocated to function view. 
ORGANIZATION VIEW - WHO, WHERE: the class of organization view creates the hierarchical organization structure. This view is created in order to group responsible entities (department, team, position, person, role) or devices executing the same work object.

DATA VIEW - WHAT, WHEN: this view comprises the data processing environment as well as the messages triggering functions or being triggered by functions.

OUTPUT VIEW -WHAT: output view contains all physical and non-physical input and output, including funds flows.

ARIS PROCESS VIEW- WHAT, HOW, WERE, WHO, WHEN, WHY: relationships among the all views, as well as the entire business process, are modelled and documented in this view.

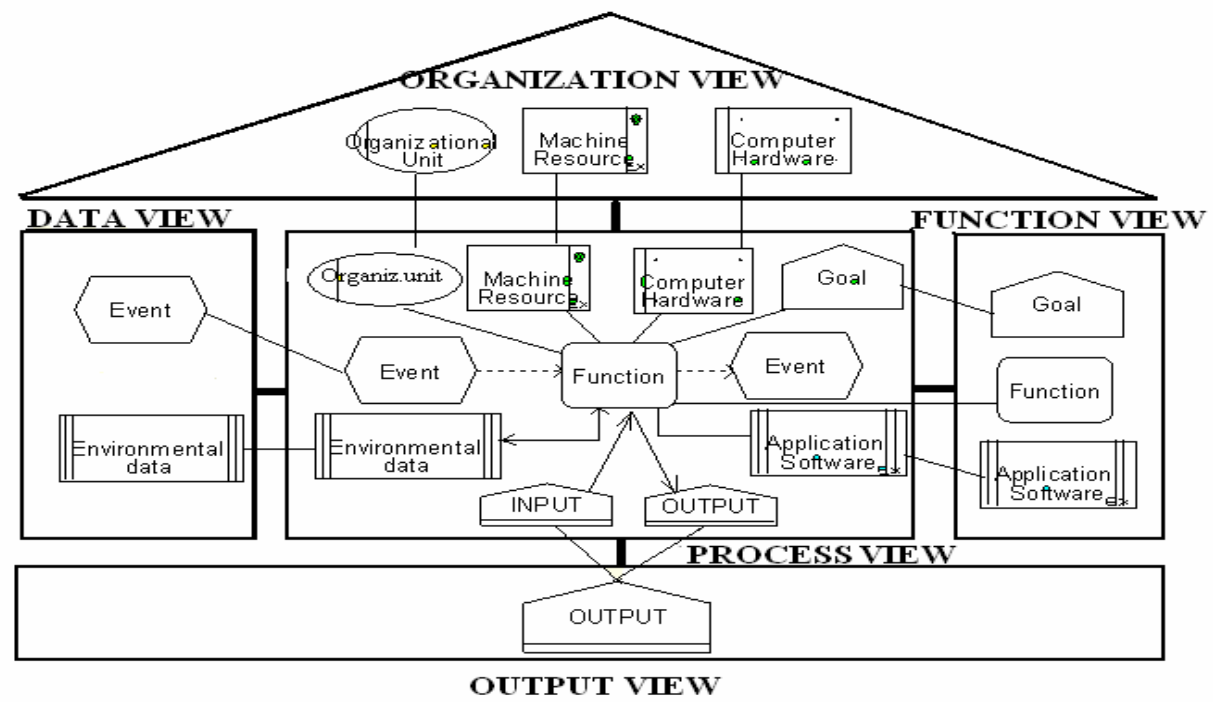

Figure 4. Views of the ARIS business process meta-model

In addition to the five views (vertical dimension), ARIS involves a concept of different description levels (horizontal dimension). As it is presented in Figure 5, these five levels represent design aspects according to the well-established software engineering lifecycle. 


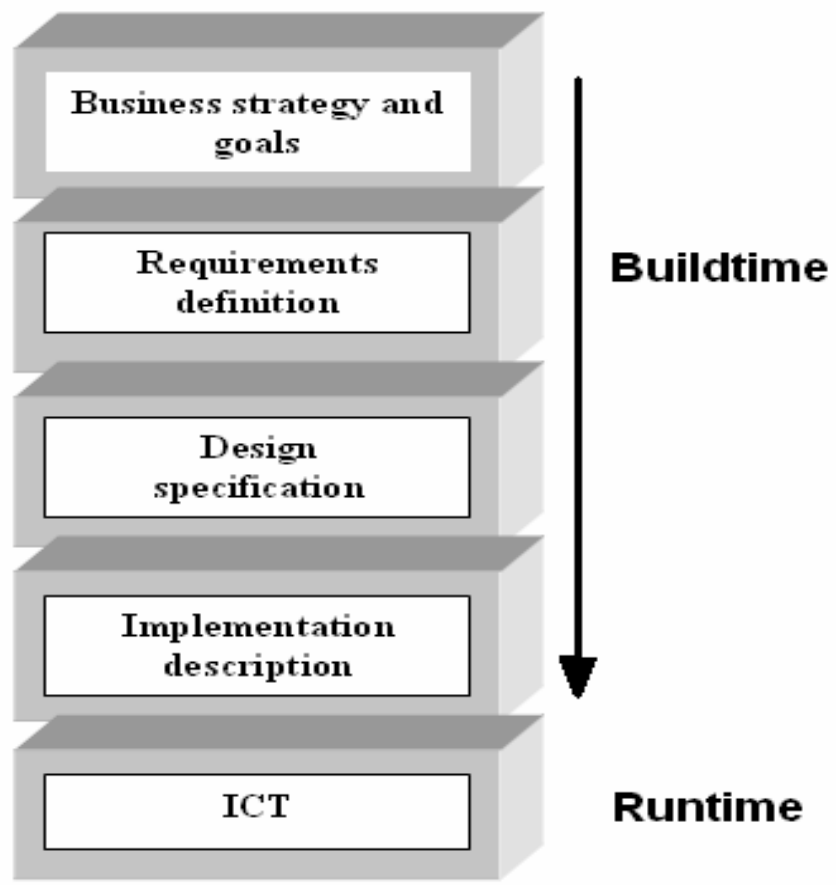

Figure 5. ARIS phase concept (levels)

The source point of this concept is the business strategy and strategic goals (level 1) defined in accordance with the vision and mission of the business system. Goals and global business processes (enterprise areas), resources and potential effects of IS implementation supported by new ICT technologies, are determined during the phase of strategic planning. The second phase, requirements definition (level 2), is related to business process modelling and ICT requirements specification (generally $\rightarrow$ databases, application software, hardware, networks, etc.) This is the most important phase of integral system development, since the model of business technology represents the starting point in IS development and its implementation. Thanks to developed methods (especially ARIS and Casewise Corporate Modeler), it is possible to use different diagrams for business process modelling. This is especially important considering the fact that the business process is a complex unit and it is difficult to show all its aspects using one model (diagram). The third phase, design specification (level 3), features the beginnings of gradual transformation of business descriptions into ICT objects. The logical IS model is developed and ICT components described in more detail (database models, hardware and network specifications, software modules, etc.) Actual IT products are still irrelevant. Phase 4, implementation description (level 4), contains descriptions of the technological model of the future system, and business requirements are implemented into actual hardware and software components. These phases of IS development are known as "buildtime" phases. Subsequently, the completed system becomes operable, meaning it is followed by an operations phase, known as "runtime". 
Thus, this dimension establishes the physical linkage from business strategy to information technology through translation from a strategic to an operational level.

The implementation of business models in information systems represents a modern approach in the development of integral business systems. The ARIS architecture accomplishes this by linking its business aspects (ARIS VIEWS) with the phase concept (ARIS LEVELS). In this way, the views of meta-business process model are valid for all descriptive levels. Figure 6 shows the ARIS architecture of an integral business system. This ARIS "House" illustrates the 15 component of this framework.

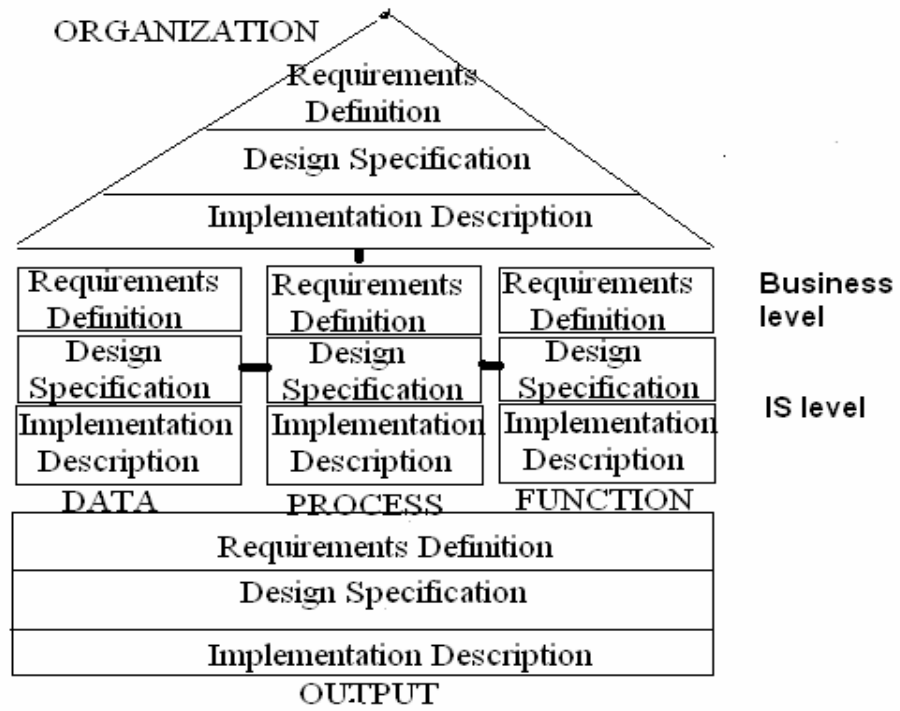

Figure 6. The ARIS architecture

\subsubsection{Aris modelling techniques}

The ARIS framework is supported by the tool of the same name and the methodology containing various modelling techniques. These modelling techniques (and their relationship with additional techniques) enable the development, analysis and optimization of enterprise architecture. In table 1, adequate modelling techniques for each ARIS component are recommended.

ARIS provides an extensive number of model types to build complex enterprise architectures. These model types represent different modelling methods. Though each model type has its own modelling objects (entity types, classes, functions or objectives), all objects are integrated in one comprehensive meta-model. This meta-model is the conceptual foundation of ARIS and inter-relates each and every model type. 
Table 1: ARIS modelling techniques (ARIS Toolset)

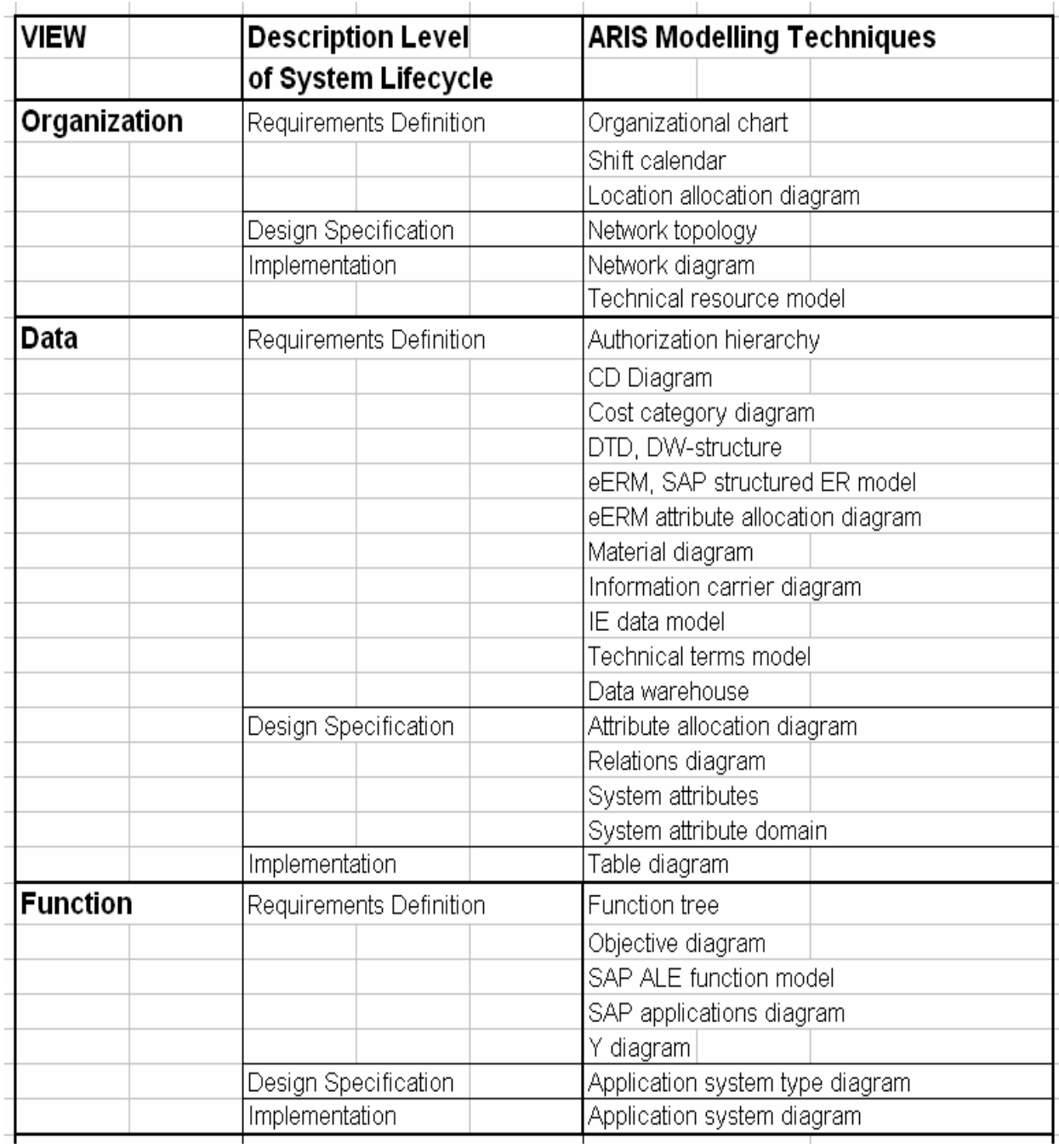




\begin{tabular}{|c|c|c|c|}
\hline Control/Process & Requirements Definition & \multirow{2}{*}{\begin{tabular}{|l} 
Authorization map \\
Business framework
\end{tabular}} & \\
\hline & & & \\
\hline & & \multicolumn{2}{|c|}{ Business control diagram } \\
\hline & & \multicolumn{2}{|c|}{ c 3 method; class diagram } \\
\hline & & \multicolumn{2}{|c|}{ Classification diagram } \\
\hline & & \multicolumn{2}{|c|}{ Communications diagram } \\
\hline & & Competition model & \\
\hline & & DW-transformation & \\
\hline & & \multicolumn{2}{|c|}{ E-Business scenario diagram } \\
\hline & & \multicolumn{2}{|c|}{ Extended event driven process chain (eEPC) } \\
\hline & & Event diagram & \\
\hline & & \multicolumn{2}{|c|}{ Function allocation diagram } \\
\hline & & \multicolumn{2}{|c|}{ Function/Organizational level diagram } \\
\hline & & Industrial process & \\
\hline & & \multicolumn{2}{|l|}{ Information flow diagram } \\
\hline & & Input/Output diagram & \\
\hline & & \multicolumn{2}{|c|}{ Knowledge Structure diagram } \\
\hline & & Material flow diagram & \\
\hline & & Office process & \\
\hline & & Privileges diagram & \\
\hline & & \multicolumn{2}{|c|}{ Process selection diagram; Process matrix } \\
\hline & & \multicolumn{2}{|c|}{ Product/Service exchange diagram } \\
\hline & & \multicolumn{2}{|c|}{ Role diagram; Rule diagram } \\
\hline & & SAP ALE models & \\
\hline & & Screen design & \\
\hline & & UML models & \\
\hline & & \multicolumn{2}{|c|}{ Value-added chain diagram } \\
\hline & Design Specification & \multicolumn{2}{|c|}{\begin{tabular}{|l|l|} 
Access diagram \\
\end{tabular}} \\
\hline & & Program flow-chart & \\
\hline & & \multicolumn{2}{|l|}{ Program structure chart } \\
\hline & & Screen diagram & \\
\hline & & Data flow diagram & \\
\hline & Implementation & \multicolumn{2}{|c|}{ Hardware/software allocation diagram } \\
\hline
\end{tabular}

\subsection{THE ZACHMAN FRAMEWORK}

The Zachman concept is another framework for modelling, evaluation, optimization, management and documenting of the integral business system. Figure 7 shows the Zachman architecture of the integral business system [1, 10]. Table 2 shows basic characteristics of the Zachman architecture with respect to development and implementation of the business model into the IS model.

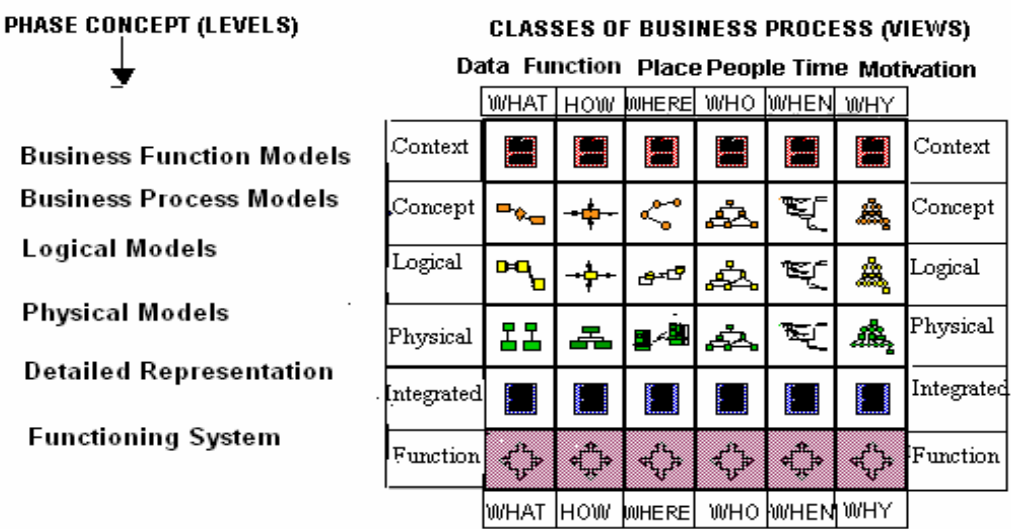

Figure 7. The Zachman architecture
Business

level

IS level 
Table 2. Characteristics of the Zachman concept in the building enterprise architecture

\begin{tabular}{|c|c|c|c|c|c|c|}
\hline $\begin{array}{l}\text { VEWS }= \\
\text { LEWTIS }=7\end{array}$ & DATA (WHAT) & PROCESS (HOW) & PLACE (WHERE) & PEOPLE (WHO) & TTME (WHEN) & MOTTVATION (WHV) \\
\hline $\begin{array}{l}\text { Business } \\
\text { Function } \\
\text { Modelling } \\
\text { (Enterprise Areas) }\end{array}$ & $\begin{array}{l}\text { High-level } \\
\text { data clasess } \\
\text { related to each } \\
\text { function }\end{array}$ & $\begin{array}{l}\text { High-level business } \\
\text { functions } \\
\text { (Enterprise Areas) }\end{array}$ & $\begin{array}{l}\text { Locations related } \\
\text { to each function }\end{array}$ & $\begin{array}{l}\text { Stakeholders } \\
\text { related to each } \\
\text { function }\end{array}$ & $\begin{array}{l}\text { Events related to } \\
\text { each function }\end{array}$ & $\begin{array}{l}\text { Business } \\
\text { objectives and } \\
\text { perfomance } \\
\text { measures related } \\
\text { to each function }\end{array}$ \\
\hline $\begin{array}{l}\text { Business } \\
\text { Process Models }\end{array}$ & $\begin{array}{l}\text { Business } \\
\text { data }\end{array}$ & $\begin{array}{l}\text { Business Processes } \\
\text { (Business Dynamics } \\
\text { Model) }\end{array}$ & $\begin{array}{l}\text { Locations } \\
\text { related to each } \\
\text { process }\end{array}$ & $\begin{array}{l}\text { Organization } \\
\text { roles and } \\
\text { responsibilities } \\
\text { in each process }\end{array}$ & $\begin{array}{l}\text { Events related to } \\
\text { each process }\end{array}$ & $\begin{array}{l}\text { Policies, } \\
\text { procedures and } \\
\text { standards for } \\
\text { each process }\end{array}$ \\
\hline Logical Models & $\begin{array}{l}\text { Logical data } \\
\text { model }\end{array}$ & $\begin{array}{l}\text { Logical } \\
\text { representation of IS } \\
\text { (System Dynamics } \\
\text { Model) }\end{array}$ & $\begin{array}{l}\text { Logical network } \\
\text { model }\end{array}$ & $\begin{array}{l}\text { Logical } \\
\text { represenation of } \\
\text { access privileges } \\
\text { constrained by } \\
\text { roles } \\
\end{array}$ & $\begin{array}{l}\text { Logical events and } \\
\text { their triggered } \\
\text { responses } \\
\text { constrained by } \\
\text { business events and } \\
\text { their responses } \\
\end{array}$ & $\begin{array}{l}\text { Policies, procedures } \\
\text { and standards } \\
\text { associated with a } \\
\text { business rule model }\end{array}$ \\
\hline $\begin{array}{l}\text { Physical } \\
\text { Models }\end{array}$ & $\begin{array}{l}\text { DBHS type } \\
\text { requirements } \\
\text { constrained } \\
\text { by logical } \\
\text { data models }\end{array}$ & $\begin{array}{l}\text { Specification of } \\
\text { applications that } \\
\text { operate on particular } \\
\text { technology platiorms } \\
\text { (Function Dynamics } \\
\text { Modell }\end{array}$ & $\begin{array}{l}\text { Specification of } \\
\text { network devices } \\
\text { and their } \\
\text { relationships } \\
\text { within physical } \\
\text { boundaries }\end{array}$ & $\begin{array}{l}\text { Specification } \\
\text { access privileges } \\
\text { to speciftc } \\
\text { plattorms and } \\
\text { technologies }\end{array}$ & $\begin{array}{l}\text { Specification of } \\
\text { triggers to respond } \\
\text { to system events } \\
\text { on specific } \\
\text { platfomis and } \\
\text { technologies }\end{array}$ & $\begin{array}{l}\text { Business rules } \\
\text { constrained by } \\
\text { IS standards }\end{array}$ \\
\hline As Built & $\begin{array}{l}\text { Data definition } \\
\text { constrained by } \\
\text { physical data } \\
\text { models }\end{array}$ & $\begin{array}{l}\text { Programs coded to } \\
\text { operate on specific } \\
\text { technology platforms }\end{array}$ & $\begin{array}{l}\text { Hetwork devices } \\
\text { configured to } \\
\text { conform to node } \\
\text { specifications }\end{array}$ & $\begin{array}{l}\text { Access privileges } \\
\text { coded to control } \\
\text { access to specific } \\
\text { platfomis and } \\
\text { technologies }\end{array}$ & $\begin{array}{l}\text { Thiming definitions } \\
\text { coded to sequence } \\
\text { actiuities on specific } \\
\text { platfomms and } \\
\text { technologies }\end{array}$ & $\begin{array}{l}\text { Business rules } \\
\text { constrained by } \\
\text { specific technology } \\
\text { standards }\end{array}$ \\
\hline $\begin{array}{l}\text { Functioning } \\
\text { Enterprise }\end{array}$ & $\begin{array}{l}\text { Data values } \\
\text { stored in actual } \\
\text { databases }\end{array}$ & $\begin{array}{l}\text { Functioning } \\
\text { computer } \\
\text { instructions }\end{array}$ & $\begin{array}{l}\text { Sending and } \\
\text { receiving } \\
\text { messages }\end{array}$ & $\begin{array}{l}\text { Personnel and key } \\
\text { stakeholders } \\
\text { working within their } \\
\text { roles anid } \\
\text { responsibilities }\end{array}$ & $\begin{array}{l}\text { Timing definitions } \\
\text { operating to } \\
\text { sequence activities }\end{array}$ & $\begin{array}{l}\text { Operating } \\
\text { characteristics of } \\
\text { specific } \\
\text { technologies }\end{array}$ \\
\hline
\end{tabular}

Meta-classes of the business process (aspects of business modelling) are also divided into individual views in the Zachman architecture in order to reduce the business model complexity. Main description views in Zachman's concept are: data-process-place-people-time-motivation. The phase concept of this architecture includes a number of levels in relation to the ARIS architecture. Buildtime lifecycle in the Zachman architecture contains the following phases: business function modelling-level 1; business process models- level 2; logical models (IS model)level 3; physical models (IS model)-level 4; "As Built" IS models-level 5. Runtime phase is related to functioning enterprise-level 6.

\section{COMPARISON AND EVALUATION OF ARIS AND ZACHMAN FRAMEWORKS - FINDING THEIR COMPLEMENTARITY}

In this chapter we compare the ARIS and the Zachman frameworks and determine their complementarities. The following criteria are defined in order to accomplish this:

a) Consistent framework for modelling, analyzing and optimizing the enterprise architecture;

b) Two dimensional structure;

c) Drill-down approach;

d) Multi-user repository; 
e) Adequacy of using ARIS modelling techniques within Zachman's framework.

\subsection{CONSISTENT FRAMEWORK FOR MODELLING, ANALYZING AND OPTIMIZING THE ENTERPRISE ARCHITECTURE}

ARIS/Zachman frameworks supported by adequate integrated tools and methods enable improvement teams to build a complete visual model of the enterprise architecture (address the organization in its entirety). Main business aspects within the model of enterprise architecture are business processes, the people that perform them, the location where they occur, applications that support the business processes and manipulate relevant data and used technology (the IT hardware and network). These business aspects are shown on Figure 8.

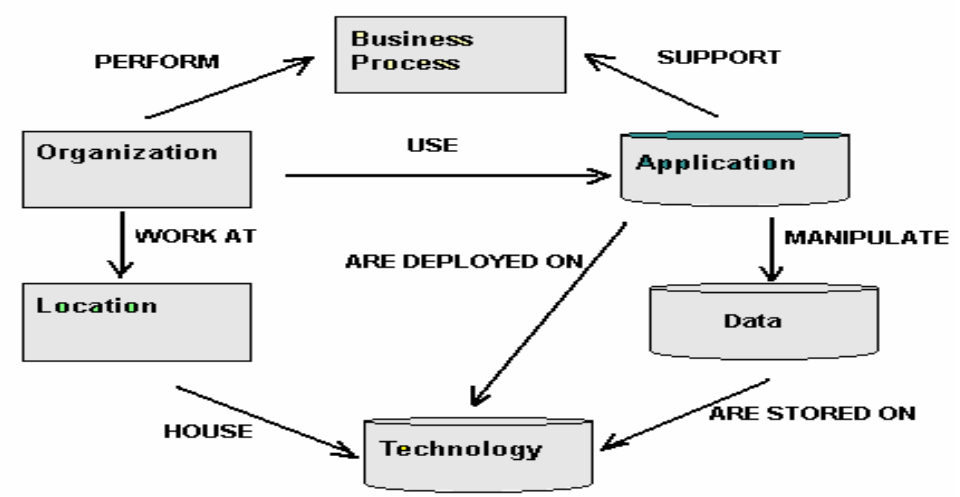

Figure 8. Main business aspects within the model of enterprise architecture

In co-relation with the above, the ARIS/Zachman frameworks supported by integrated tools and methods link together the business process, organizational aspects, IT architecture and data modelling through a multi-user repository.

Organizational/hierarchical modelling: form a top-down view of the organization within the scope of improvement initiatives; structures organizational entities and their roles in the realization of business processes.

Business process modelling/analysis/simulation [2,4]: visualize and improve business processes using easy-to-understand modelling notation; ensure jobs flow through departments, systems, suppliers from initial customer enquiry through to final delivery of product/service; analyze the "AS-IS" model, design the "TOBE" model (shown on Figure 9); to accomplish this, they use various assessment procedures, reference models, and of special importance, simulation methods, which research the dynamics of business processes in order to locate inefficiencies and quantify the benefits of "what-if" scenarios. 


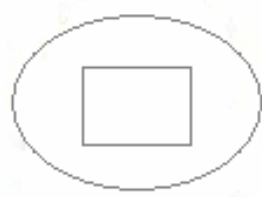

'As-is' model

\section{Collaborative} improvement

Figure 9. Business Process Improvement

There are numerous reasons which point to the importance of creating models of business processes. Here are some of them:

- To get a picture of the existing process and all its aspects (business process meta-classes),

- To measure, monitor and evaluate business processes (quality, expenses, time, flexibility, allocation of resources, redundancy, "what-if" assessment, etc.),

- To make an adequate optimization of the business process in question using various methods (reference models, best practices, simulation, benchmarking)

- To structure the ISO 9001:2000 quality management system,

- To allow for the development of own integrated IS or to customize standard software solutions.

IT Architecture modelling: optimizes how the business applications, hardware, networks and data structures align to support or automate the business processes; design where and how to integrate or replace existing systems to maximize ROI (return on investment).

Data flow modelling: analyzes how information is shared across an organization to perform business processes; create a hierarchical set of data flow diagrams (DFDs) to show data flows at every level of operations.

Data modelling: analyzes and improves the use of data at each step of business process; implement data design or analyze how existing data structures support the business.

\subsection{TWO-DIMENSIONAL STRUCTURE}

Both approaches have a similar design paradigm, as they both include a twodimensional framework. The six vertical dimensions (descriptive views) in Zachman's framework are analogous to the views in the ARIS concept. Thus, both frameworks decrease the complexity of modelling the business technology and 
facilitate modelling within the following perspectives: what, how, where, who, when, why. In addition, the six horizontal dimensions (descriptive levels) in Zachman's framework are analogous to the levels (software lifecycle concept) in the ARIS concept. Their vital importance is to connect the complete business model with the IS model.

\subsubsection{Views - reduction of complexity in modelling business technology}

According to Zachman's framework, we can distinct 6 aspect of business technology: data, time, network, people, function and motivation. The ARIS concept is primarily focused on business processes, data, functions and organization (shown on Fig. 4). Data and functions correspond directly with the Zachman's Framework. The time aspect of Zachman's framework is implicitly part of the data view in ARIS concept, because the modelling object "event" represents stages of business objects in terms of time and logical sequence. In this context, messages trigger the functions or being triggered by functions. The organization view in ARIS concept captures both, people and location (network) on different levels of modelling. In addition, objective diagrams within the function view in ARIS cover the motivation field in Zachman's framework. All vertical description views of Zachman's framework can be found in ARIS framework. Determined complementarities of ARIS and Zachman frameworks according to this criterion are shown on Fig. 10.

\begin{tabular}{|l|l|l|l|l|l|}
\hline $\begin{array}{l}\text { Zachman } \\
\text { framework } \\
\text { (VIEWS) }\end{array}$ & $\begin{array}{l}\text { DATA } \\
\text { What }\end{array}$ & $\begin{array}{l}\text { TIME } \\
\text { When }\end{array}$ & $\begin{array}{l}\text { NETWORK } \\
\text { Where }\end{array}$ & $\begin{array}{l}\text { PEOPLE } \\
\text { Who }\end{array}$ & $\begin{array}{l}\text { FUNCTION } \\
\text { How }\end{array}$ \\
\hline ARIS VIEWS & $\begin{array}{l}\text { MOTIVATION } \\
\text { Why }\end{array}$ \\
\hline $\begin{array}{l}\text { INTEGRATION } \\
\text { IN ARIS }\end{array}$ & DATA view & ORGANIZATION view & FUNCTION view \\
\hline
\end{tabular}

Figure 10. Vertical comparison and evaluation of ARIS/Zachman frameworks

ARIS framework includes the integrative and the dynamic process view. Integrating the other views constitutes the process view. This leads to a high level of consistency of the enterprise architecture.

The four main ARIS views (organization, data, function, process) ensure that enterprise architectures can be captured in its completeness and from various aspects. These aspects as the main business drivers within the enterprise architecture are: business (processes, organization, location), applications, information and technology.

\subsubsection{Levels - integration of business model and is model}

Descriptive levels (horizontal dimension of both frameworks) ties the business model and the IS model. In that context, we can place these levels in two 
categories: the business level and the IS level. According to Zachman's framework, we differentiate between 6 levels, while the ARIS framework supports 5 levels. Complementarities of ARIS and Zachman frameworks recognized according to this criterion are shown in Fig. 11.

The "Scope (contextual)" level in u Zachman's framework corresponds to the "Business strategy (business goals)" level of the u ARIS framework. Strategic goals are formed within these levels, as well as global business areas (enterprise areas), and global effects of IS implementation are estimated. The "Enterprise model (conceptual)" level in Zachman's framework corresponds to the "Requirements definition" level of ARIS, and this level is significant due to detailed modelling of business processes and planning of information needs, which are determined within the said level. Listed levels all refer to the business level.

Furthermore, the development of the integrated business system is furthered by the development of the logical IS model (level 3 in both frameworks). Levels like "Technological model of the system" and "Full system integration" in Zachman's framework correspond to the "Implementation description" level of the ARIS concept. These levels refer to the IS level. Both approaches support the runtime level, "Functioning system".

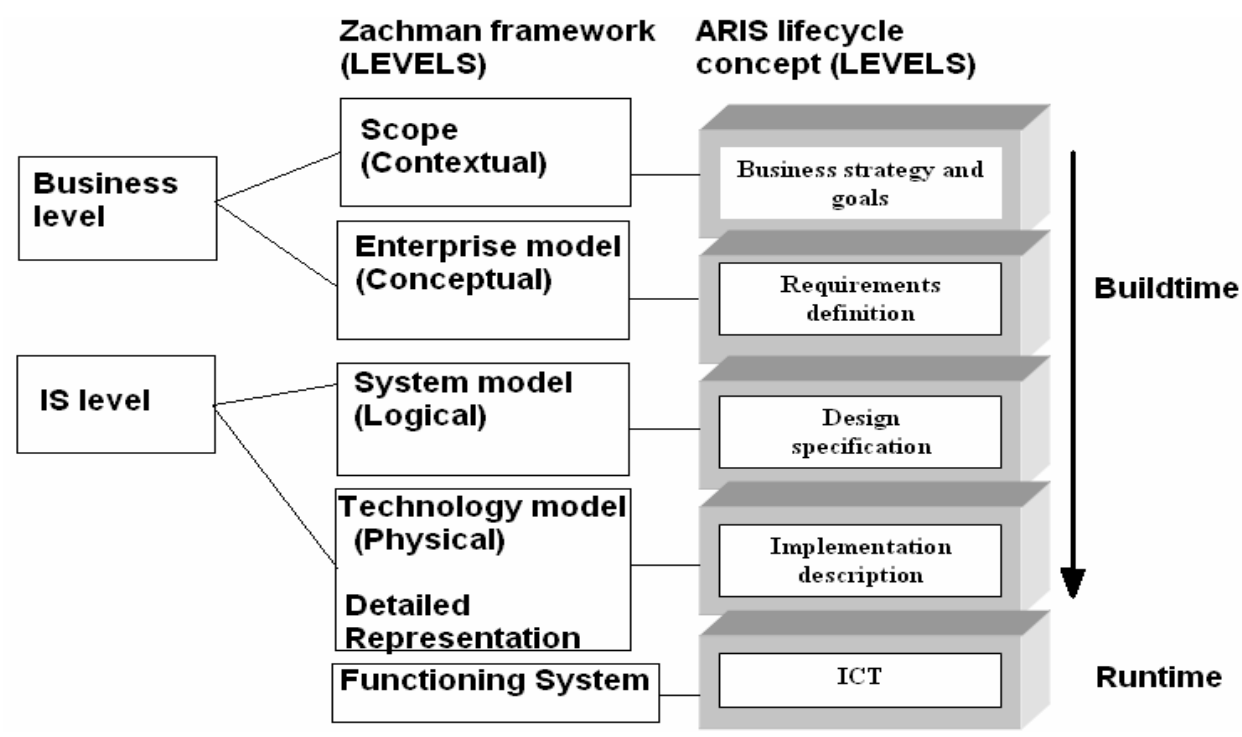

Figure 11. Horizontal comparison and evaluation of ARIS/Zachman frameworks

Both approaches allow drilling down from a strategic to an operational level by providing a map, which covers the complete cycle from strategy to implementation of information systems. These lifecycle concepts for information systems connect the described levels (areas) and support their interrelations. 


\subsection{DRILL DOWN APPROACH}

Drilling down approach enables us to navigate down from high-level overviews to low-level processes, so we can present architecture at the appropriate level of detail.

Multi-level process modelling allows us to develop process models from the global hierarchy structure; first in the higher level models (business level), then in the lower levels (IS level). Each level of process modelling is supported by the relevant data model and the model of technological architecture. This can be observed in most detail on the physical level of IS. Fig. 12 shows the drill down approach supported by the ARIS/Zachman frameworks.

In addition, drill across approach enables us to link from the end of one business process to the start of the next.

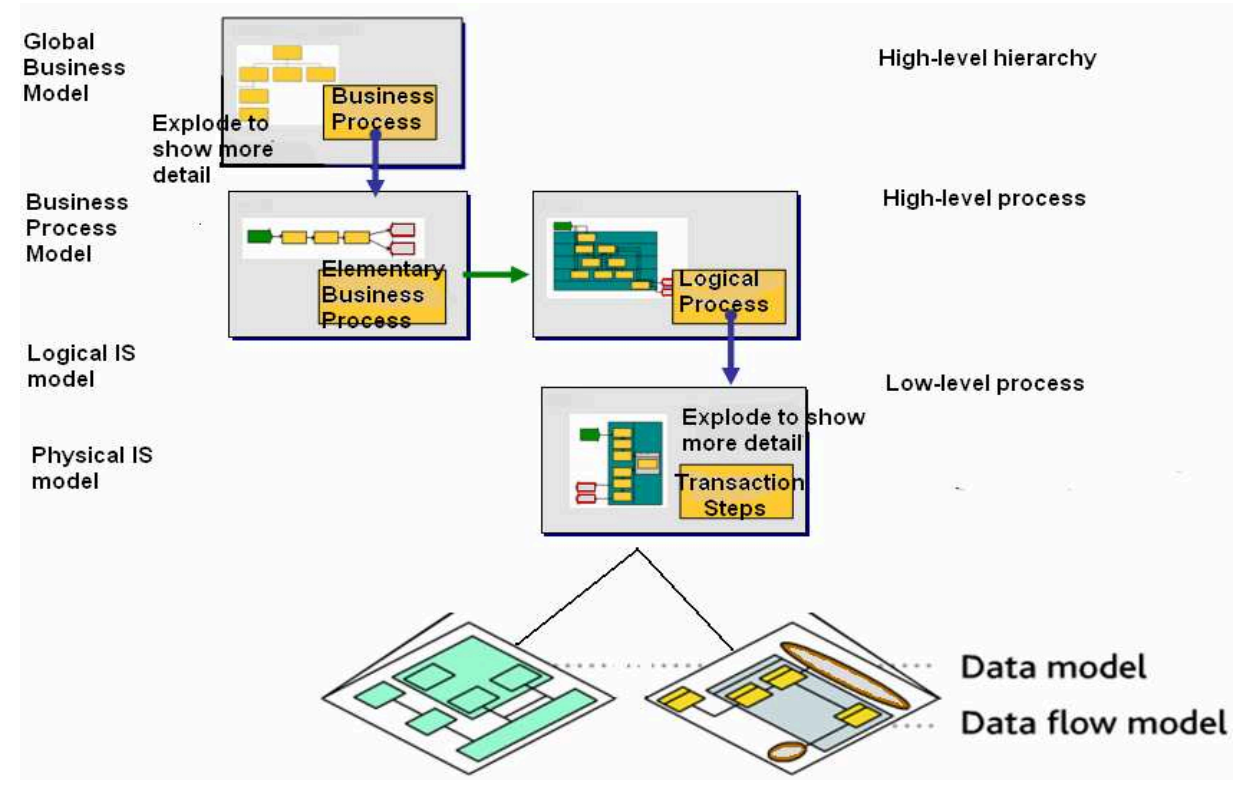

Figure 12. Drill down approach

\subsection{MULTI-USER REPOSITORY}

Both frameworks (ARIS i Zachman) are developed so that they can incorporate integrating tools and modelling techniques which are grouped in a single, unique data base - the multi-user repository. When we create the business object representing a certain business aspect (process, organization, data, application, IT architecture), we save its main attributes in the data base (capture key business knowledge). That same object may be used by any member of the project team in any model that the object appears in (reuse objects). This provides a coherent approach to business improvement, where all users are working with a common set 
of objects representing the enterprise. The functionality also induces reuse of bestpractice processes across the organization.

Due to the possibility related to reusing objects throughout models, keeping models up-to-date is quick and easy. We can update an object in any one part of a model, for all other occurrences of that object to instantly be updated. In this way, we can identify all the areas of the organization that would be impacted by changing one component of the business.

\subsection{ARIS MODELLING TECHNIQUES CAN BE UTILIZED WITHIN ZACHMAN'S FRAMEWORK}

Of great importance for more effective enterprise architecture management are the methods and the tools supporting the concepts, i.e. frameworks for enterprise architecture. The ARIS framework is supported by the said methods and integrating tools. There are methods and tools supporting the Zachman's framework as well (for example, the Corporate Modeler/Casewise). Since the goal of this paper is to determine certain points of complement between the ARIS and Zachman frameworks, this Chapter deals with the possibilities of using ARIS modelling techniques within Zachman's framework. ARIS is able to capture a complete picture of data, applications, organizations and processes based on integrated modelling techniques and tools. The ARIS concept can be regarded as complementing Zachman's concept and captures its dimensions in a very similar way. According to the two-spanned congruent dimensions of the ARIS and the Zachman frameworks, it is possible to utilize ARIS modelling techniques within the Zachman framework. Figure 13 shows how some of ARIS modelling techniques (as shown in Table 1) can be suitable within Zachman's framework. ARIS' main advantage lies in the integrative process/control view (integrating all modelling objects of the other views). Overall, both approaches are highly complementary. 


\begin{tabular}{|c|c|c|c|c|c|}
\hline & & VIEW & ORGANI & ATION VIEW & FUNCTION VIEW \\
\hline & $\begin{array}{l}\text { DATA } \\
\text { (What) } \\
\end{array}$ & $\begin{array}{l}\text { TIME } \\
\text { (When) }\end{array}$ & $\begin{array}{l}\text { PLACE } \\
\text { (Where) }\end{array}$ & $\begin{array}{l}\text { PEOPLE } \\
\text { (Who) }\end{array}$ & $\begin{array}{l}\text { FUNC TION MOTIVATION } \\
\begin{array}{ll}\text { (How) } & \text { Why) }\end{array}\end{array}$ \\
\hline $\begin{array}{l}\text { Business } \\
\text { Function } \\
\text { Models } \\
\text { (Context) }\end{array}$ & & Busi & hess frat & nework & \\
\hline $\begin{array}{l}\text { Business } \\
\text { Process } \\
\text { Models } \\
\text { (Concept) }\end{array}$ & $\begin{array}{l}\text { Data } \\
\text { Mater } \\
\text { eERI }\end{array}$ & $\begin{array}{l}\text { ehouse } \\
\text { diagram }\end{array}$ & $\begin{array}{l}\text { Organ } \\
\text { Chart } \\
\text { Locati } \\
\text { allocat }\end{array}$ & $\begin{array}{l}\text { zational } \\
\text { on diagram } \\
\end{array}$ & $\begin{array}{l}\text { Function tree } \\
\text { Objective diagram }\end{array}$ \\
\hline $\begin{array}{l}\text { Logical } \\
\text { Models } \\
\text { Plnysical } \\
\text { Models } \\
\\
\text { Det ailed } \\
\text { Represent }\end{array}$ & $\begin{array}{l}\text { Relat } \\
\text { Syste } \\
\text { Table }\end{array}$ & $\begin{array}{l}\text { s diagram } \\
\text { attributes } \\
\text { agram }\end{array}$ & $\begin{array}{l}\text { Netwo } \\
\text { Techn } \\
\text { resour }\end{array}$ & $\begin{array}{l}\text { k topology } \\
\text { cal } \\
\text { ce model }\end{array}$ & $\begin{array}{l}\text { Application system } \\
\text { type diagram } \\
\text { Application system } \\
\text { diagram }\end{array}$ \\
\hline $\begin{array}{l}\text { Functioning } \\
\text { System }\end{array}$ & data & schedule & networl & organizati & on application \\
\hline
\end{tabular}

Figure 13. ARIS modelling techniques within Zachman's framework

\section{BUSINESS SYSTEM MANAGEMENT SUPPORTED BY ARIS AND ZACHMAN FRAMEWORKS}

The goal of the paper comes through in this chapter as defining the general phases (levels) of the business system management and examining the applicability of ARIS and Zachman frameworks as complementary architectures to these levels. General process management system phases may be described through the following levels [4,5,11]: at level 1 (process design/redesign); at level 2 (process planning and control); at level 3 (workflow control); at level 4 (application system). Figure 14 shows the global model for business system management supported by ARIS/Zachman architectures. 


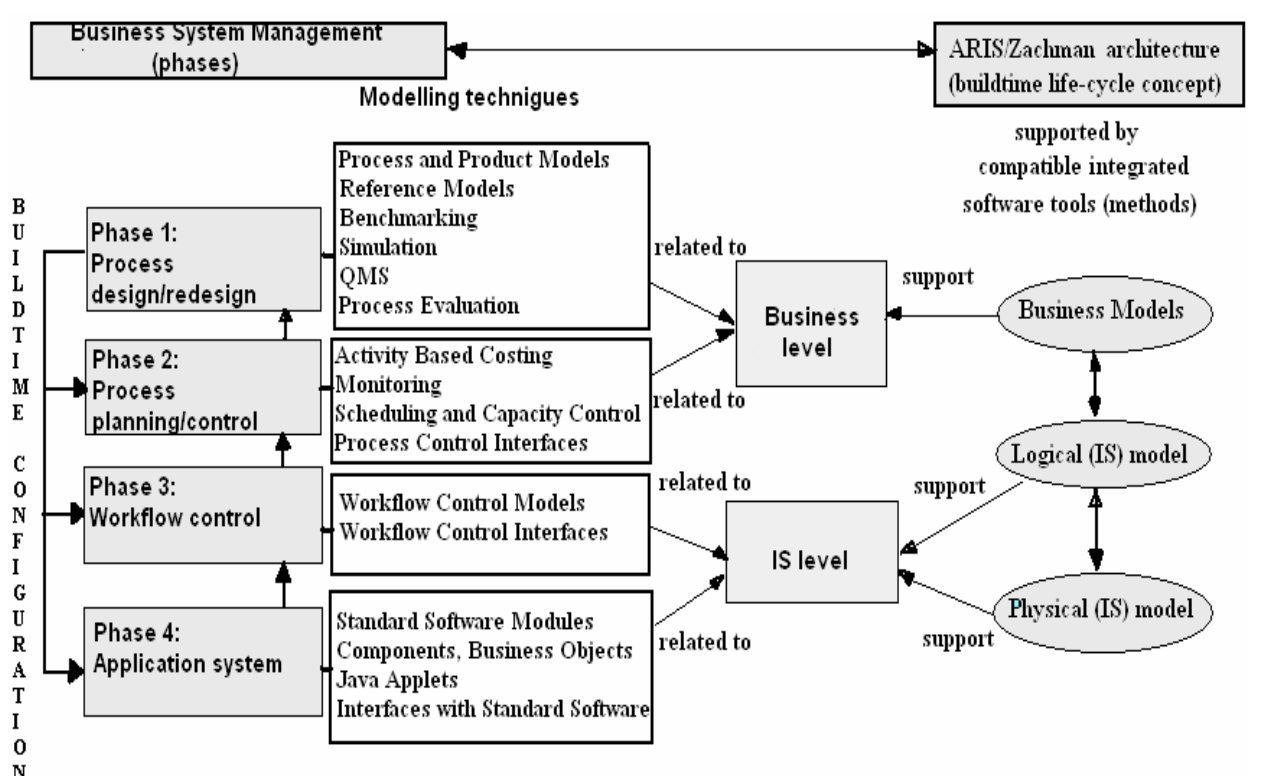

Figure 14. Business system management supported by ARIS/Zachman architectures

Complementary frameworks for enterprise architectures such as ARIS and Zachman frameworks support the business system management from organizational engineering to IT implementation, including continuous process improvement. This all becomes possible through the use of integrated software tools and methods. Phases of a business system management may be described/listed as follows:

Process design/redesign: business processes are modelled using various modelling techniques, and they cover all aspects of business modelling; various methods for optimizing, evaluating and ensuring the quality of the processes are also available.

Process planning and control: current business processes are planned and controlled by means of different methods for scheduling and capacity, cost analysis methods (activity based costing (ABC)), and other methods for quality control and business process success.

Workflow control: converts business processes into IT tools. Generally, it is not possible to administer an entire business process with one application software system. Often, a variety of systems for sales, purchasing, manufacturing, accounting is necessary. It therefore makes sense to allocate the responsibility for comprehensive process control to an explicit system level rather than distributing it across several systems. This phase is called "workflow". Workflow systems pass the documents to be processed from one work place to the next. In general, business technology flows are made up of data exchanged by business processes and the defined source and destination of their exchange; business processes are just key points in the transformation of information and data. At this phase, ARIS/Zachman architectures and compatible workflow modelling techniques provide prototyping functionality and interfaces with different workflow systems. 
Application systems: documents delivered to the workplaces are specifically processed, i.e. functions of the business process are executed using computer-aided application systems-ranging from simple processing systems to complex standard software solution modules-business objects and java applets. Traditional standard software solutions are transaction driven, integrated business application systems. The main idea of componentware is to assemble software systems from individual standard components developed by various vendors. Today, new application software is generally developed using object oriented technologies. At this phase, generic business objects for logistics solutions are available, in addition to interfaces for starting standard software solutions.

Process design/redesign and process planning/control phases refer to the business level, whereas workflow control and application system phases refer to the IS level. With software installed at all levels of business system management, the ARIS/Zachman life cycle model is applicable to all levels (phases). Therefore, these architectures can be used for managing business processes from organizational engineering to IT implementation, including continuous process improvement.

Phases (levels) of business system management are interlinked by two-way communication. Using the top down approach, the model of business processes is implemented into the relevant IS (phase concept of integral business system). Accordingly, the business system model is the starting point of IS development. Using the bottom up approach, one achieves feedback from lower levels of management toward the higher ones, such as process control and process evaluation levels. Feedback is sought (and achieved) in order to facilitate new optimization and continuous improvement of business processes, i.e. the entire system (continuous system improvement). For example, process control delivers information on the efficiency of current processes. Workflow control reports actual data on the processes to be executed (amounts, times, organizational allocations) to the process control level. Each new optimization of business processes (business process reengineering) requires new business concepts which will be implemented into the relevant IS during the next (new) cycle.

\section{CONCLUSION}

Enterprise architectures provide the platform for business system management. They are an important starting point for various initiatives requiring IT support based on clearly specified business objectives. Building and managing enterprise architectures will not be successful without a stable and consistent enterprise architecture framework supported by compatible integrated tools and methods.

ARIS and Zachman enterprise architecture frameworks pave the way for engineering, planning and controlling business processes, optimization and continuous business process improvement. These concepts aid in capturing a wide range of descriptive aspects of business processes, allocating relevant methods to them. Understanding the what, how, who, where, when and the why is very important for the build-time life-cycle concept of IS. This paper analyzes the main aspects of the meta-business process for both concepts (called the ARIS/Zachman 
views). Views of said architectures decrease the complexity of business process modelling. However, the ARIS/Zachman architectures surpass the process architecture and enhance it using the phase concept, which starts with the business level and ends with the IS implementation level (called the ARIS/Zachman levels).

Furthermore, the paper contains the definitions of criteria for the comparison and evaluation of these two concepts, aimed at finding certain complementarities and advantages of each of the concepts. The criteria are categorized thusly: a consistent framework for modelling, analyzing and optimizing the enterprise architecture; two dimensional structure; drill-down approach; multi-user repository; and modelling techniques.

Both approaches were developed independently, but they are highly complementary. The ARIS framework is able to depict all dimensions and levels of the Zachman framework. In comparison to the Zachman framework, ARIS has a particular advantage. ARIS includes the integrative process/control view that integrates all modelling objects of the other views. This leads to a high level of consistency of the enterprise architecture.

By analyzing the details of the ARIS/Zachman architectures complement, the paper aims to offer an analysis of their applicability through the all phases (levels) of the business system management (business and IS levels). In accordance with the above, the paper further strives to define the global model for business system management supported by the ARIS/Zachman architectures. With software installed at all levels of business system management, the ARIS/Zachman life cycle model is applicable to all levels (phases). In conclusion, these architectures can be used for managing business processes from organizational engineering to IT implementation, including continuous process improvement.

\section{REFERENCES:}

[1] Hokel, T.A.: The Zachman Framework for Enterprise Architecture :An Overview, Available from: http://www.frameworksoft.com/web-sitedownloads/FSI-Enterprise-Architecture-Overview-Paper.pdf, Copyright 19932005, Accessed: 2005-04-20.

[2] Perkins, A. (1997): Enterprise Information Architecture, White Papers, Available from: http://www.ies.aust.com, Accessed: 2005-04-15.

[3] IDS Scheer (2005): Enterprise Architectures and ARIS Process Platform, White Papers, Available from: http://www.changeware.net/doc/wp_ea.pdf, Accessed: 2005-12-10.

[4] Scheer, A.W. (1999): ARIS - Business Process Frameworks, $3^{\text {rd }}$ edition, Berlin et al.

[5] Scheer, A.W. (1999): ARIS - Business Process Modeling, $3^{\text {rd }}$ edition, Berlin et al. 
[6] Schekkerman,J. (2005): Trends in Enterprise Architecture 2005: How are Organizations Progressing?, EA Survey, Institute for Enterprise Architecture Developments, Available from: http:/www.enterprise-architecture.info/ Images/EA\%20Survey/Enterprise\%20Architecture\%20Survey\%202005\% 20IFEAD\%20v10.pdf, Accessed: 2005-12-10.

[7] Spiekermann, S.(2004): System Analysis and Modelling with ARIS, Available from: http://www.wiwi.hu-berlin.de/ sspiek/ITSD_VL5.ppt, Accessed: 2005-04-10.

[8] Sowa,JF., Zachman J.A.(1992): Extending and formalizing the framework for information systems architectures, IBM Systems Journal, 31(3), pp.590-616.

[9] Ulrich F.(2002): Multi-Perspective Enterprise Modeling (MEMO) - Conceptual Framework and Modeling Languages, Proceedings of the $35^{\text {th }}$ Hawaii International Conference on System Sciences

Availablefrom http://csdl2.computer.org/comp/proceedings/hicss/2002/ 1435/03/14350072.pdf; Accessed: 2005-12-13.

[10] Zachman,J.A. (1996): Concepts of the Framework for Enterprise Architecture, White Papers, Available from: http://www.ies.aust.com

[11]Business Process Management Exchange (2004), Report, Available from: http://www.iqpc.com/binary-data/IQPC_CONFEVENT/pdf_file/6565.pdf, Accessed:2005-04-20.

Received: 23 November 2005

Accepted: 28 June 2006 